\title{
Proksimal tibia kapalı kama osteotomisi: Plak ile tespit
}

\author{
Proximal tibia closed wedge osteotomy: fixation by plate and screws
}

\author{
Hüseyin S. Yercan
}

Manisa Celal Bayar Üniversitesi Tıp Fakültesi, Ortopedi ve Travmatoloji Anabilim Dalı, Manisa

Yüksek (proksimal) tibial osteotomi tek kompartmanı tutan diz osteoartrozunda başarılı ve etkin tedavi seçeneği olmuştur. Bu prosedürün amacı ağrının giderilmesi, hareketin korunması yanında total diz artroplastisi zamanını geciktirmesidir. Geniş hareket açıklığına ve sağlam diz stabilitesine sahip genç ve aktif hastalar, yüksek tibial osteotomi ameliyatı için en uygun hasta grubunu oluştururlar. Cerrahlar kendi kişisel tercihleri, varusun derecesi, bağ ve patella baja gibi anormal biyomekanik özellikleri de hesaba katarak açık kama ve kapalı kama teknikleri arasında seçim yaparlar.

Anahtar sözcükler: diz; osteoartrit; osteotomi; kapalı kama
1

961 yılında Jackson ve Waugh, tibia üst ucunda tuberositas tibianın distalinden yapılan osteotomiyi tanımlamıştır. Bunu hala günümüzde yaygın olarak kullanılan Coventry'nin tuberositas tibianın proksimalinden yaptığı lateral kapalı kama osteotomisi izlemiştir (PTKKO). ${ }^{[1]} 1965$ yılında Yüksek Tibial Osteotominin (YTO) prensiplerini belirleyen Coventry'nin kuralları hala günümüzde geçerliliğini korumaktadır. Bunları sıralayacak olursak; 1) Deformite tam hatta fazladan düzeltilmelidir, 2) Osteotomi deformitenin yakınından yapılmalıdır, 3) Osteotomi bölgesi hızla iyileşebilmelidir, 4) Tespit erken hareket ve yüklenmeye izin verecek kadar stabil olmalıdır, 5) Uygulanması kolay olmalıdır. Osteotominin tuberositas tibianın proksimalinde yapılmasının nedeni, kuadriseps kas gücü ve onun devamı olan ligamentum patellanın çekme gücüyle osteotominin stabilitesine olan dinamik katkısından yararlanılmasıdır. YTO, proksimal tibial osteotomi (PTO) olarak da isimlendirilmektedir.
High (proximal) tibial osteotomy has been considered as a successful and effective treatment for unicompartmental knee osteoarthritis. The main goals of this procedure are to relieve the pain, to protect the knee motion and activity, and to delay the need for a total knee arthroplasty surgery. The relatively young and active patients who have good knee mobility and stability, are always proper indication for the high tibial osteotomy. Surgeons make decision between two techniques-open or closed wedge-based on personal preference, degree of varus alignment, additional biomechanical abnormality such as ligament laxity and patella baja.

Key words: knee; osteoarthritis; osteotomy; closed wedge
YTO için ideal endikasyonları şöyle sıralayabiliriz:

1- Göreceli genç yaş veya aktif hasta

2- Yakınmanın çoğunluğunun aktivite ağrısı olması

3- Varus açısal deformitesi

4- Tek kompartmanı tutan osteoartroz

5- Patellofemoral ekleme ait yakınmaların ılımlı olması ya da hiç bulunmaması

6- Stabil diz

7- Dizin tam ekstansiyon ve en az $90^{\circ}$ fleksiyon hareket genişliğine sahip olması.

Bunun yanında YTO için sakıncaları şöyle sıralayabiliriz:

1- Önceden geçirilmiş travma ve cerrahiye bağlı instabilite

2- Lateral kompartmanda fazla aşınma bulguları (kemik ve kıkırdak kaybı ile karakterize)

- İletişim adresi: Prof. Dr. Hüseyin S. Yercan, Manisa Celal Bayar Üniversitesi Tıp Fakültesi, Ortopedi ve Travmatoloji Anabilim Dalı, Manisa Tel: 0532 - 6681388 e-posta: yercanhes@yahoo.com

- Geliștarihi: 20 Ocak $2020 \quad$ Kabul tarihi: 7 Mart 2020 
3- $20^{\circ}$ 'nin üzerindeki ekstansiyon kaybı ve $90^{\circ}$ 'nin altında fleksiyon derecesi

4- $20^{\circ}$ 'nin üzerindeki varus açılanması

5- İleri osteoartroz

6- Inflamatuar kökenli artritler

7- Ciddi dolaşım bozuklukları

\section{BAŞARILI BIR YTO IÇiN GEREKENLER}

1- Ameliyat öncesi statik ve dinamik ölçümlerin yapılması

2- Düzeltme açısının belirlenmesi. Hastanın morfotipi ve ırksal özelliklerinin dikkate alınıp, ligamentöz instabilite varlığının ortaya koyulması

3- Uygun tekniğin seçimi

4- Ameliyatta sağlanan düzeltmeden emin olunması ve uygun tespitle bu düzeltmenin korunması

5- Düzeltmenin geç kaybından kaçınılması

\section{Uygun Tekniğin Seçimi}

Yapılacak operasyon, uygulanması kolay, ucuz, hastaya erken hareket imkânı veren, düşünülen düzeltme açısını güvenli bir şekilde sağlayan ve tibia üst ucunu en az deforme eden yöntem olmalıdır.

\section{Proksimal Tibia Kapalı Kama Osteotomisi (PTKKO)}

Lateral PTKKO'de; yapıldığı yer (tuberositas tibianın arkasından veya proksimali), şekil (transvers veya oblik) ve tespitte kullanılan yöntemin (alçı, U çivisi, plak-vida veya eksternal fiksatör) osteotominin stabilitesine ve amaçlanan derecede kaynamasına katkısı vardır. Tibia üst ucunu bir şampanya bardağına benzetebiliriz. Yumuşak spongioz kemiği çevreleyen kortikal kısım mekanik olarak serttir. Yeterli fiksasyon (tespit) desteği yoksa ve periferdeki korteks karşılığını bulamadıysa osteotomi bölgesinde düzeltmenin kaybıyla karşılaşılabilinir. PTKKO'de stabilite için önemli nokta medial kortikal ve yumuşak doku devamlılığın bozulmamasıdır. ${ }^{[2,3]}$

\section{Avantajları:}

1- $15^{\circ}$ 'ye kadar rahat düzeltme

2- Stabil tespit ile erken hareket

3- Dizde fleksiyon ve malrotasyon deformitesi yaratma riski az

4- Patellofemoral eklemi gerektiğinde düzeltme şansı mevcut

\section{Dezavantajları:}

1- Fibula osteotomisi ve bunun getirdiği sorunlar: Başlıca fibula başının rezeksiyonu, proksimal tibiofibular bağın kesilmesi, fibula boyun veya diafız osteotomileri tanımlanmıştır. Özellikle ilk ikisi cerrahi sonrasında dış yan bağ laksisitesi ile sonuçlanabilir. ${ }^{[4]}$ Fibula boyun osteotomisinde ise cerrahi sahadan geçen peroneal sinirin yaralanma olasılığı diğer büyük riski oluşturur.

2- Daha fazla cerrahi disseksiyon.

3- Ekleme yaklaşıldığında kırık oluşma riskinde artış ve osteotomi yerinde basamaklaşma

4- Tibia üst ucunda yaptığı morfolojik değişiklik

5- Bacakta kısalma. Gerçekte çıkarılan kemiğin kısalık yapacağı düşünülse de varus açılanmasının düzeltilmesiyle bu sorun ortadan kalkabilir.

6- Patella baja ve artmış $Q$ açısı. ${ }^{[5]}$

\section{Literatürdeki Uygulanan Lateral Kapalı Kama Osteotomi Tipleri}

\section{Proksimal lateral transvers kapalı kama osteotomisi}

Mümkün olan en büyük temas yüzeyi ile hızlı kaynama şansını verir. Tespitte bir ya da iki tane $U$ çivisine ek olarak mutlaka alçı destek gerekir. Bu yöntem ile Gerdy tüberkülüne yapışan tensor fasia lata zarar görebilir ve zaten zayıf olan lateral gergi sistemi daha da kötüleşebilir. Osteotomi hattı ekleme oldukça yakın olduğundan, eklem içi kırık ve proksimal parçanın osteonekroz riski mevcuttur. Insall'un bahsettiği gibi bu komplikasyonların osteotomi sonrasında gelişebilecek kötü sonuçlar ile bağlantısı vardır. ${ }^{[6]}$ Ayrıca büyük kama çıkartılması gereken durumlarda osteotomi yüzeylerindeki eşitsizlikten dolayı belirgin basamaklaşma oluşabilir. YTO'nin bazı hastalar için zaman kazandırı$\mathrm{cı}$ operasyon olduğunu düşünürsek, TDA ile revizyonu gündeme geldiğinde tibial komponentin yerleştirilmesinde zorluk oluşabilir. ${ }^{[3]}$

\section{Tuberositas tibia düzeyinde yapılan transvers kapalı kama osteotomisi}

Osteotominin tespitinde $U$ çivisi, plak-vida sistemi ve eksternal fiksatör kullanan yöntemler mevcuttur. Osteotomi hattında oluşacak basamaklaşma deformite yaratabilir. Bu deformiteyi ortadan kaldırmak için distal parçanın laterale çekilmesi medial devamlılığı bozarak osteotominin stabilitesini bozabilir. ${ }^{[3]}$

\section{Oblik lateral kapalı kama osteomisi}

Bu teknikte ostetomi yüzleri eş uzunluktadır. Böylece herhangi bir basamaklaşma oluşmaz ve tibia üst ucunun şekli korunmuş olur. ${ }^{[3]}$ Kendi pratiğimizde, KKYTO uygulamalarında bu yöntemi tercih ediyoruz. 


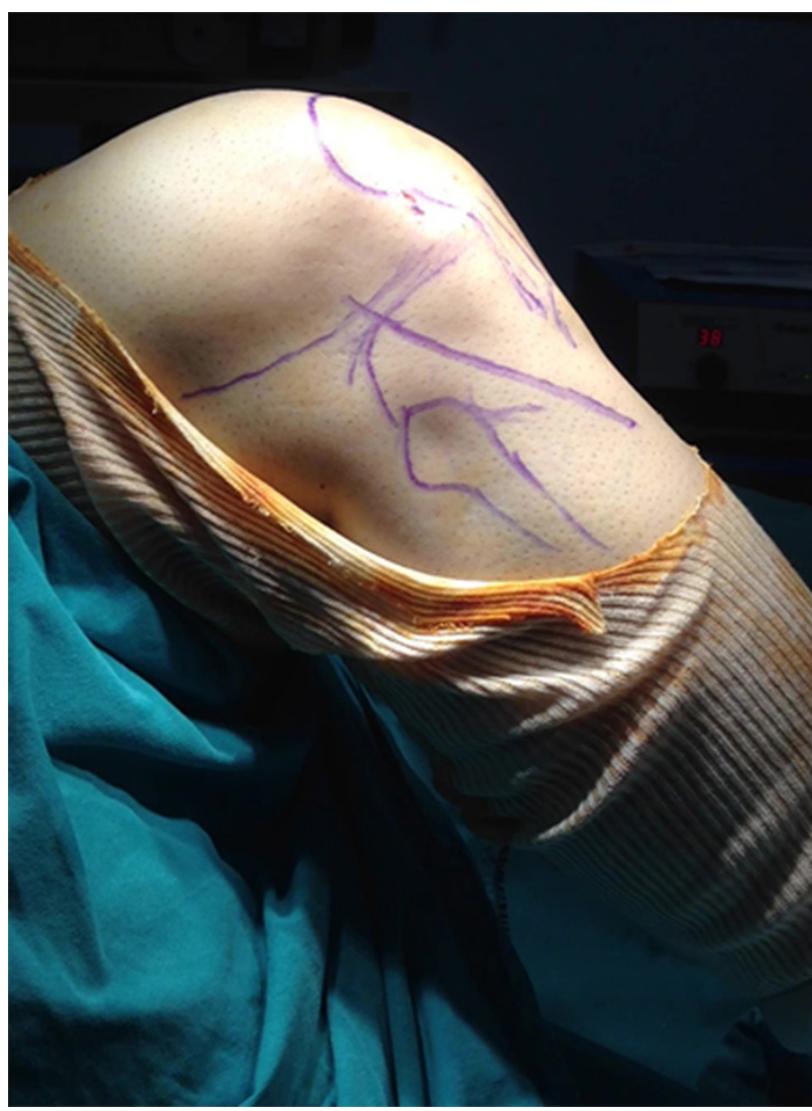

Şekil 1. Cilt kesisi: Fibula başı ile tuberositas tibia arasındaki mesafenin ortasından lateral eklem arağından başlayıp oblik olarak tibial ön kenara (crest'e) doğru uzanır.

\section{Tekniğimiz; proksimal tibia oblik kapalı kama osteotomi ve plaklı tespit, ayrıntılar}

- Uygun düzeltme açısı: Ahlback Evre 2 ve 3 osteoartrozlu hastalarda mekanik aksta ölçülen deformitenin $3^{\circ}$ 'den fazla düzeltilmesini amaçlıyoruz. Anterior laksisitesi olanlarda tarif edilen ekstansiyon ostetomisi veya ön çapraz bağ (ÖÇB) rekonstrüksiyonu ile beraber yapılan valgizasyon ostetomisinde tibial eğimi $10^{\circ}$ 'nin altına indirmeyi amaçlıyoruz. Kapalı kama osteotomileriyle tibial eğimin azaltılması ${ }^{[7]}$, açık kama osteotomilerine göre daha kolay gerçekleştirilir.

- Cerrahi kesi: Tibial tüberkül ile fibula boynu arasındaki mesafenin tam ortasından lateral eklem aralığından tibia ön kenarına doğru devamlılık gösteren oblik bir cilt kesisini tercih ediyoruz. Bu kesiyle hem fibula boyun osteotomisini hem de PTKKO'ni kolaylıkla yapabiliriz. Ayrıca cilt kesisinin gelecekte ki TDA için sorun oluşturmaması önemlidir (Şekil 1).

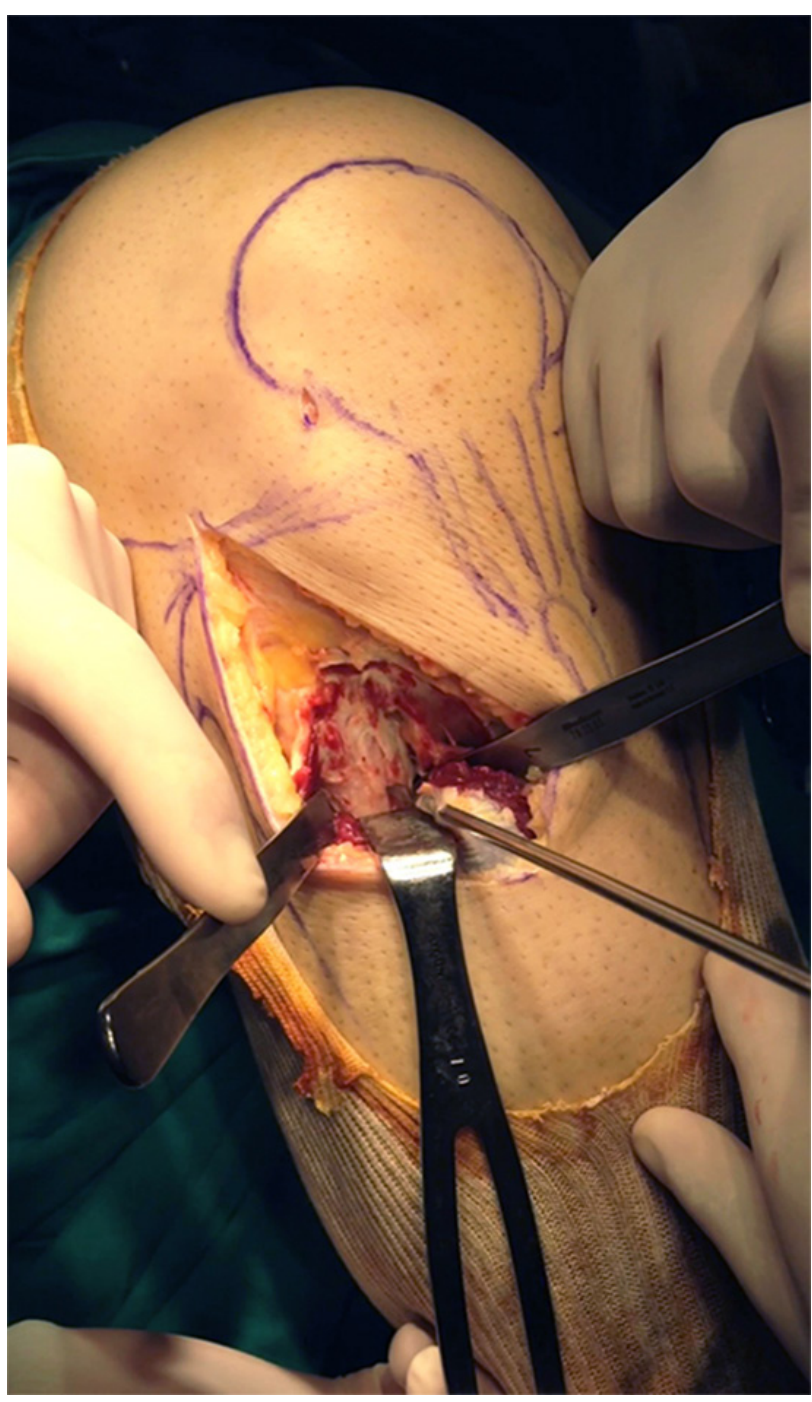

Şekil 2. Fibula boyun osteotomisi için dril ile korteksin zayıflatılması.

- Fibula ostetomisi: Fibula boynu veya distal-orta $1 / 3$ bileşkeden olmak üzere iki farklı bölgeden birini seçiyoruz. Fibula diafiz osteotomilerinde, fibulanın oblik olarak kesilip birbiri üzerinden kaymasına izin verilir. İkinci bir kesiye ihtiyaç duyulması yanında, ostetomi bölgesinde kaynamama veya geç kaynamaya bağlı ağrıdan hastaların şikâyetçi olduğunu gördük. ${ }^{[8]}$ Fibula boyun ostetomisi ile boyundan kısa bir kemik segmentin çıkarılması yeterli olacaktır (Şekil 2). Bu yöntemin ameliyat sonrası dönemde hasta için daha konforlu olduğunu düşünüyoruz. Fakat peroneal sinir yaralanma riskinden dolayı deneyimli kişilerce yapılması gerekir. Bu cerrahiye yeni başlayanlar için ostetominin distal-orta $1 / 3$ bölgeden yapılması önerilir. 


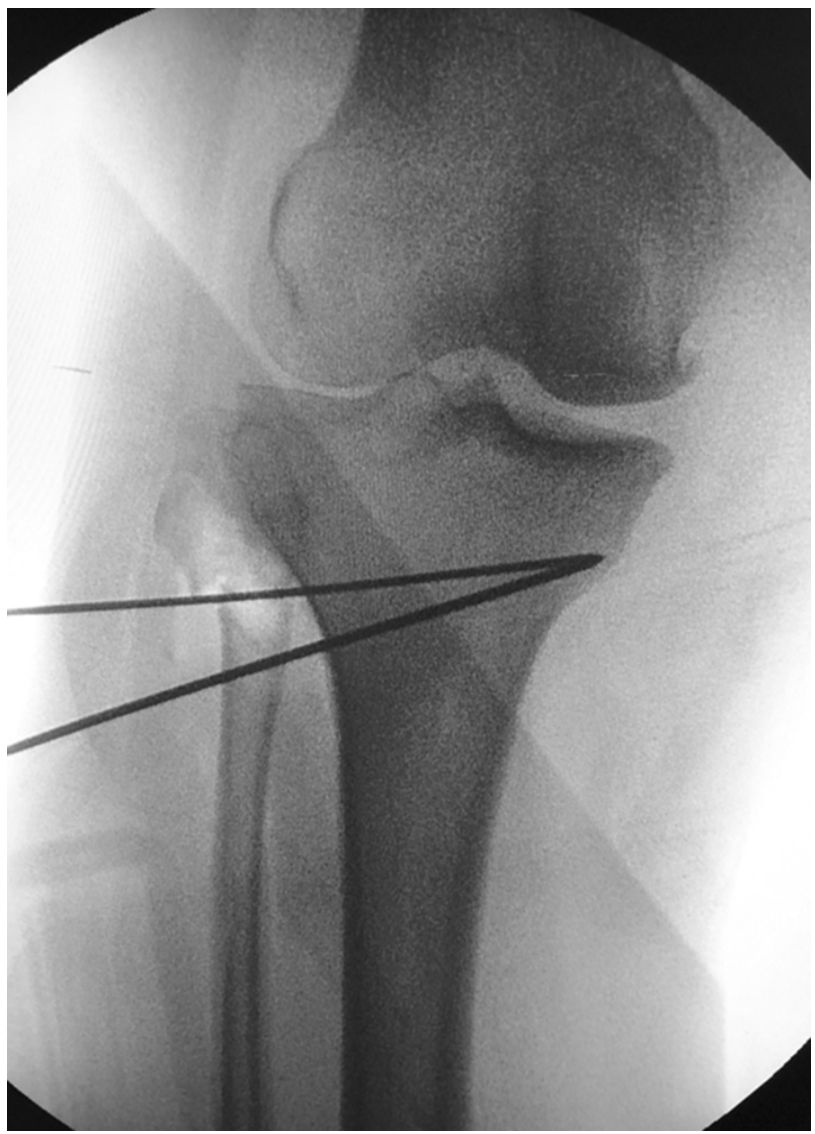

Şekil 3. Tibiadan tubersitas tibia arkasında kalarak çıkarılacak wedge (kama).

- Osteotomi şekli: Ostetominin yerleşimi tuberositas tibianın arkasıdır. Osteotominin proksimal ve distal bölümü birbirine eşit olacak şekilde yapılır. Böylelikle kemik parça çıkarılıp osteotomi yüzleri kapatıldığı zaman herhangi bir basamaklaşma ile karşılaşılmaz. Ayrıca osteotominin proksimal bölümünün lateral tibial platodan yaklaşık 3,5-4 $\mathrm{cm}$ distalinde yer alması ve medialde ise distal osteotomi kesisiyle medial tibia platosunun 2-2,5 $\mathrm{cm}$ distalinde buluşması gereklidir. Bu noktanın medial korteksten $1 \mathrm{~cm}$ lateralde yer alması medial kortikal devamlılığın sigortasıdır (Şekil 3). Osteotominin tuberositas tibianın arkasında yapılmasının temelde iki nedeni vardır (Şekil 4). illki plaklı tespit yapacağımız için osteotominin proksimalinde en az üç kilitli vidanın yerleştirilmesi için yeterli sahanın olmasına imkân verir. İkincisi ise osteotomi yapılan bölgede daha ufak osteotomi yüzleri olacağından çıkarılan kemik miktarı daha ufak olacaktır. Bu da kemik stoğunu korumamıza olanak verir.

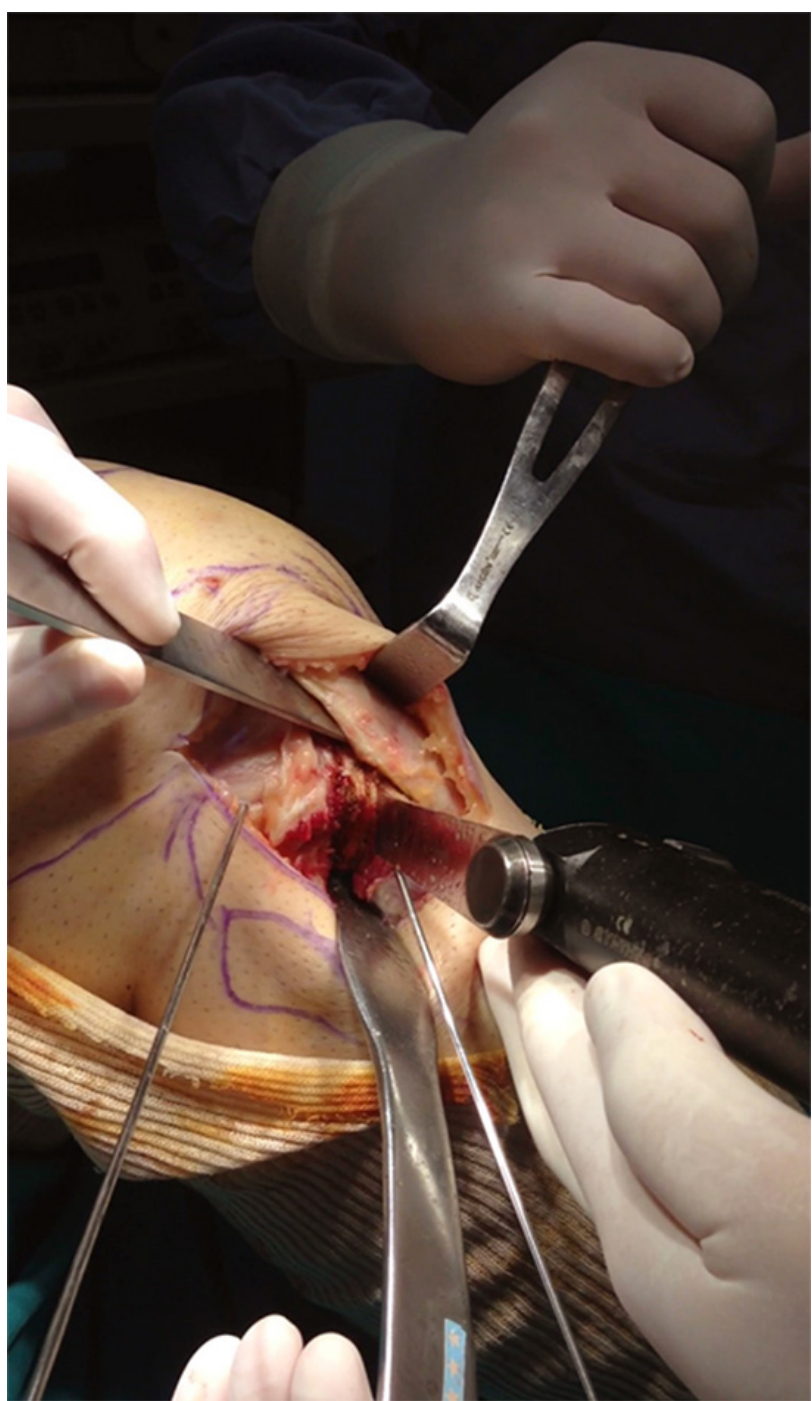

Şekil 4. Tuberositas tibianın arkasından havalı kesiciyle düzgün bir kesi yapılırken. Tuberositas tibia, arkasına yerleştirilen keskiyle korunarak, kemik wedge (kama) çıkartılır.

- Çıkarılacak kemik miktarı: Belki de en önemli sorundur. Çünkü klasik olarak söylenen her $1^{\text {'’llik }}$ düzeltme için $1 \mathrm{~mm}$ 'lik kemik çıkartma gerekliliği ancak 56-60 mm genişlikteki ostetomi yüzleri için geçerlidir. ${ }^{[9]}$ Yani bu kurala göre yapılan kesimlerde geniş tibial platolu hastalarda az düzeltme, dar ve ufak tibialı olgularda fazla düzeltme meydana gelir. Ne yazık ki kapalı kama osteotomisinde amaçlanan açı değerlerinin yakalanması açık kama osteotomilerine göre daha zordur. ${ }^{[10]}$ Özellikle kollateral instabiliteli olgularda bu ciddi bir sorundur. Oluşabilecek az veya fazla düzeltme hasta memnuniyetini etkileyen temel faktörlerdendir. 

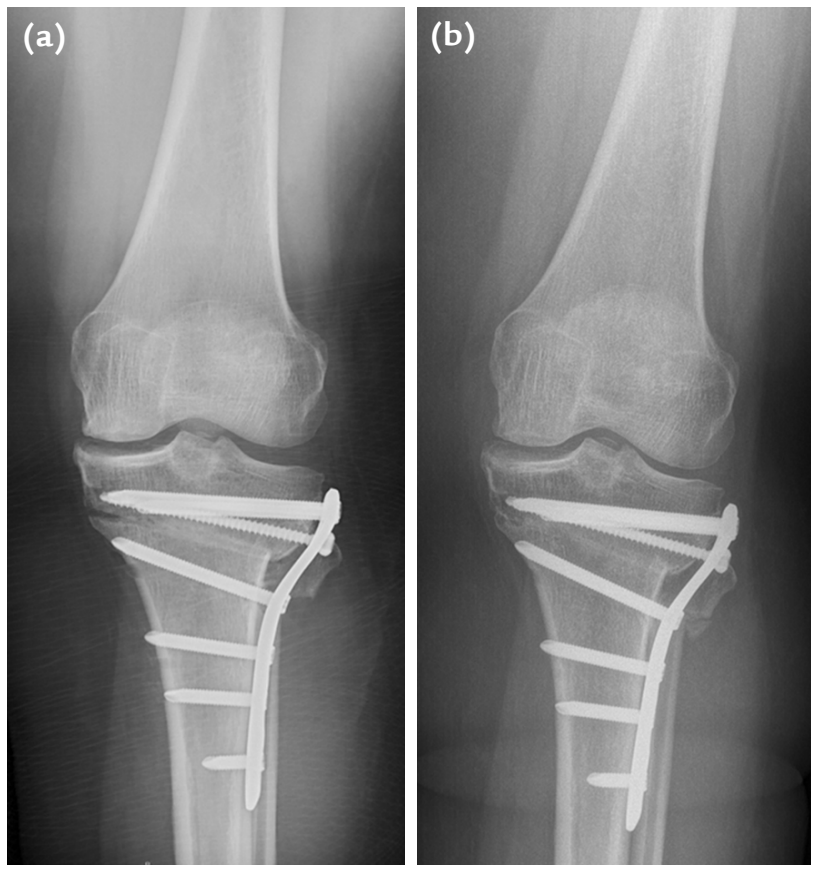

Şekil 5. a, b. Medial kortekste tespit sonrasında ki açılma, güçlü tespit materyali kullanıldığında (kilitli plak ve vida) herhangi bir problem oluşturmaz. Fakat staple gibi daha güçsüz tespitlerde bu durum tespitin bozulmasına ve varusun tekrarlamasına sebebiyet verebilir. Ameliyat sonrası (postoperatif) (a) ve üç ay sonra (b) çekilen grafilerde medial korteksteki açılmanın sorunsuz iyileşmesi gösteriliyor.

- Medial kolon devamlılığı: Osteotomi medialde kortekse gelmeden $0,5 \mathrm{~cm}$ kala ve platonun yaklaşık $2 \mathrm{~cm}$ distalinde sonlanır. Medial korteksin havalı kesici ile kesilmemesi, ancak 3,2 mm delici ucuyla açılan delikler ile zayıflatılıp bükülmesi gerekir. Bu sırada valgus zorlaması ile birlikte mutlaka topuktan itilip osteotomi sahasının sıkıştıııması gerekir. Yoksa yeterince zayıflatılmamış medial kortekste kırılma yerine parçalanma meydana gelebilir. Bu sorun ostetominin stabilitesinin tehlikeye atabilir. Fakat bizim de kullandığımız gibi, tespitte osteotominin proksimali ve distalinde yerleşecek 3-4 kilitli vida ile güçlü bir kilitli plağın kullanılması, medial kolonda ki devamsızlığın getirdiği instabilitenin üstesinden gelebilir.

- Tespitin kontrolü: Mutlaka tespit sonrasında skopi ile medialden kortikal açılmanın olup olmadığına dikkat edilmelidir. Ostetomi yüzlerinin tam olarak teması, ostetomini stabilitesi ve zamanında kaynaması için gereklidir. Özellikle ostetominin tepe noktası gerekenden daha lateralde sonlanırsa, fiksasyon sonrası medialden açma meydana gelebilir. Bu durumda medialden $U$ çivisi ile tespit sağlamlaştırılır ya da alçılı

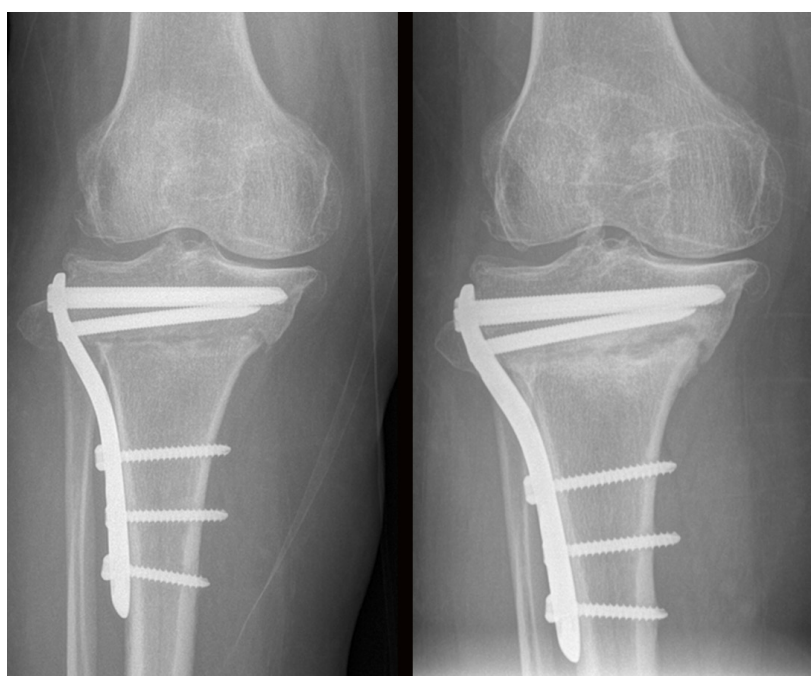

Şekil 6. Osteotomini distal parçasında medial korteks devamlılığı bozulur ve laterale kayarsa sert medial korteks olması gerektiği gibi karşılığında korteks bulamaz, stabilite bozulabilir ve elde ettiğimiz düzeltme zaman içinde kaybolabilir.

immobilizasyon gerekebilir. Ama kullandığımız kilitli plak ve yeterli sayıdaki kilitli vidalarla buna gerek kalmaz. Sadece yükten kurtarmak yeterlidir (Şekil 5). Medial kortikal devamlılıkta kontrol gerektiren diğer bir husus, distal parçanın medial kenarının proksimale göre daha lateralde yer almamasıdır. Bu oluşursa sert kortikal medial kolon proksimaldeki daha yumuşak spongioz kemik karşılığını bulursa, iyileşme sırasında düzeltme kaybı gelişebilir (Şekil 6).

- Düzeltmenin kontrolü: İstenilen açı değerinin elde edilmesi mutlaka operasyon sırasında kontrol edilir. Bunu pratik olarak skopi altında, femur başı merkezinden ve ayak bileği orta noktasında geçen koter kablosu yardımıyla yapıyoruz. Kablonun dizden lateral tibial platosunun medial 1/3'ünden geçmesi gerekir (Şekil 7). Bizce bu yöntemin tek sakıncası, yüklenme olmadığı için dış bağ laksisitesini deformiteye katkısının göz ardı edilmesidir. O yüzden kollateral instabiliteli hastalarda kapalı kama osteotomilerinde arzulanan düzeltme ve dizilimi sağlamak hep güç olmuştur. ${ }^{[11]}$

- Postoperatif dönem: Yöntemimiz sıkı tespit imkânı verdiğinden immobilizasyona gerek yoktur. Ameliyat sonrası 1. günde ilgili alt ekstremite pasif hareket cihazına koyulur, 3. günde kolaylıkla aktif $90^{\circ}$ 'lik diz fleksiyonuna ulaşılır. Hasta, günlük üç kez aktif diz fleksiyonu için teşvik edilir. Genellikle hastalar altı hafta sonunda ameliyat öncesi fleksiyonuna rahatlıkla ulaşırlar. Yüklenmeye, 6. haftada yapılan radyografi kontrolü sonrasında başlanılır. 


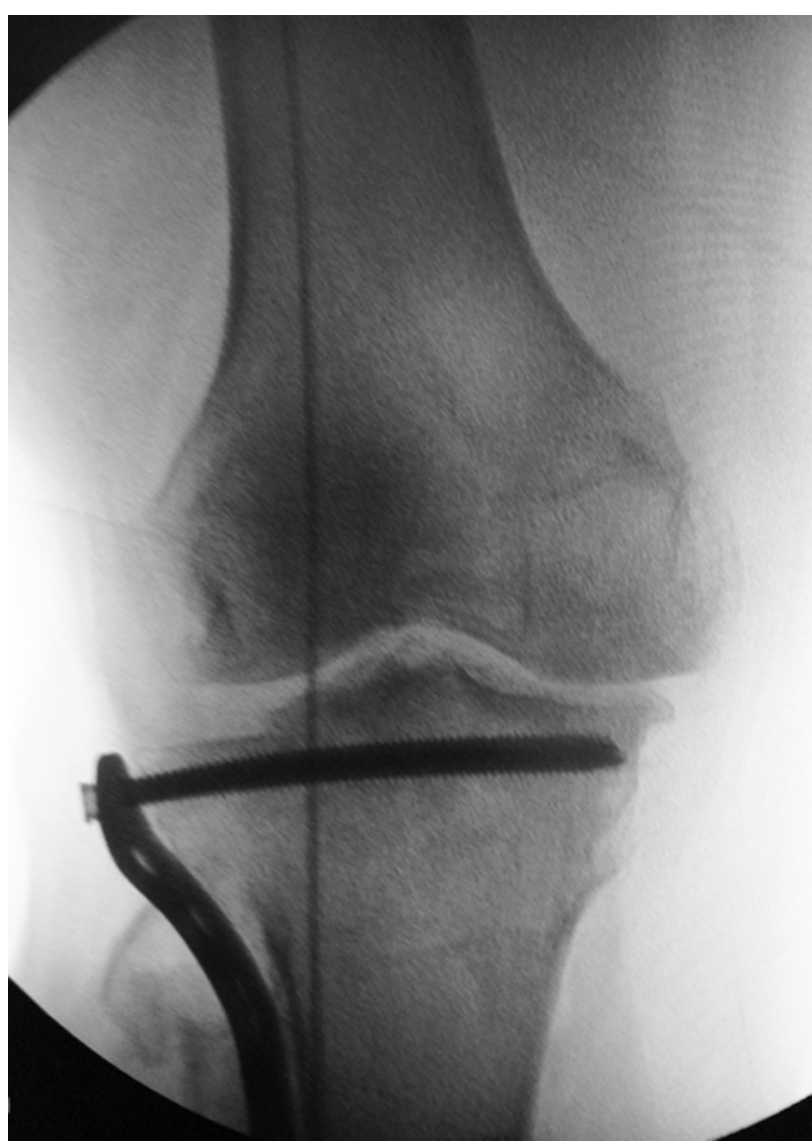

Şekil 7. Düzeltmenin yeterliliğinin kablo testi ile kontrol edilmesi gereklidir.

\section{KOMPLIKASYONLAR}

\section{Az-Aşırı Düzeltme ve Düzeltmenin Kaybı}

PTKKO'de az ya da aşırı düzeltme iyi yapılmayan preoperatif (ameliyat öncesi) planlamaya bağlıdır. Bauer'in önerdiği her $1^{\circ}$ 'lik düzeltme için $1 \mathrm{~mm}$ 'lik kemik çıkarılması her diz için uygulanamaz. Çok geniş veya dar tibia üst ucunda yanlış düzeltmeler elde edilebilir. Bununla birlikte ameliyat sırasında istenilen açı değerinin tutturulmasında güçlük yaşanabilir. Jackson ve Waugh \%35, Geiger ve ark. ise \%10 hastada istedikleri açı değerini verememişlerdir. ${ }^{[12,13]}$ Mynerts ancak \%55 hastasında uygun düzeltme sağlayabilmiştir. ${ }^{[14]}$ Holden ve ark., hastalarında ortalama $1,6^{\circ}$ 'lik hata bulmuşlardır. ${ }^{[15]}$ Osteotomi sırasında kullanılan özel aletler ve sık skopi kontrolü ile bu sorunun üstesinden gelinebilir.

Zaman içinde elde edilen düzeltmenin erken veya geç kaybı diğer bir problemdir. Aglietti ve ark. hastaların \%10'unda zamanla varusun tekrarladığını bildirmiştir. ${ }^{[16]}$ Bazı yazarlar düzeltme kaybının kötü sonuçlarla ilişkisi olduğunu düşünmüştür. Bunlardan Stuart hastalarının \%15'inde, $5^{\circ}$ 'yi aşan varus tekrarı bulmuştur. ${ }^{[17]}$ Bunun aksine Rinonapoli hastalarının $\% 24^{\prime}$ 'ünde $5^{\circ}$ 'yi aşan varus bulurken deformitenin tekrarlamasının ağrının giderilmesinde etkili olmadığını savunmuştur. ${ }^{[18]}$ Özellikle epifizer varus deformiteli olgularda daha başarılı sonuçlar alındığı, eklem içi kemik aşınmasına bağı geliş̧en varus deformiteli hastalara göre sonuçların elde edilen düzeltme derecesine çok bağlı olmadığı bildirilmiştir. ${ }^{[19,20]}$

\section{Patella Baja ve Eklem Hareketinin Kısıtlanması}

Patella baja, kapalı kama ostetomisinde yetersiz tespit nedeniyle uygulanan uzun immobilizasyon sonrasında gelişebilir. Güncel implantlar ile sağlanan güvenli tespit erken rehabilitasyona imkân tanıyacak ve bu olasılık en aza inecektir ${ }^{[21,22]}$ Açık kama osteotomisinde ise patellar tendonun gerilmesi ve patellanın distalizasyonu problem yaratabilir. Özellikle hastada operasyon öncesinde patella baja varsa açık kama osteotomisinden kaçınmak gereklidir.

\section{Eklem İçi Kırık ve Osteonekroz}

Insall, proksimal kemik parçanın $2 \mathrm{~cm}$ 'den daha az bırakılmasının bu sorunları doğurabileceği bildirmiştir. ${ }^{[23]}$ Ayrıca bunun oluşumu kötü sonuca zemin hazırlar.

\section{Kaynamama}

Osteotomi sonrası kaynamama oranı oldukça düşük $(\% 1,3-3,6)$ olarak bildirilmiştir. ${ }^{[9,14,24]}$ Tuberositas tibianın altından yapılanlar ile üstünden yapılanlar arasında belirgin kaynama farkı vardır. Insall ve ark., kırık ve osteonekroz gibi komplikasyonların kaynamama için zemin hazırlayabileceğinden bahsetmiştir. [23] Proksimal parçanın boyutu cerrahi seçenekleri ve tedavinin şekli konusunda belirleyicidir. ${ }^{[25]}$ Tedavisinde kemik grefti ve rijid (katı) tespit önerilir.

\section{Enfeksiyon}

Ciddi derin enfeksiyon oranı oldukça az ve genelde eksternal fiksatör kullanımı ile beraberdir.

\section{Peroneal Sinir Yaralanmaları}

Fibular ostetomi bölgesine göre peroneal sinir yaralanmaları görülebilir. Peroneal sinirin fibula boynunu döndüğü bölüm ile fibulanın $68-160$ mm'lik bölümü ekstansör hallusis longus (EHL) kasının motor sinirinin peroneal sinirden ayrıldığı cerrahi risk alanlarıdır. ${ }^{[26,27]}$ Müller, deneyimli cerrahlar tarafindan uygulanan fibula boyun ostetomisinde peroneal 
felç riskinin düşük olduğunu bildirmiştir. ${ }^{[3]}$ Aydoğdu ve ark. ile Kirgis ve ark., fibula diafiz ostetomisinin ortadistal 1/3 bileşkeden yapılmasının daha güvenli olacağını göstermiştir. ${ }^{[26,27]}$ Fibulanın distal-orta $1 / 3$ bileşkeden yapılan osteotomisinde peroneal sinirin yüzeyel dalının yaralanma şansı mevcuttur. Fakat dikkatli cerrahi ile bu en aza indirilir.

\section{Kompartman Sendromu}

Kesin oranı bilinmemektedir. Peroneal sinir disfonksiyonlarının bir kısmından sorumlu tutulmuştur. Dikkatli cerrahi, iyi kanama kontrolü ve osteotomi bölgelerinden drenajın sağlanması gereklidir. Özellikle fibula diafiz osteotomilerinde peroneal damarlarda oluşabilecek yaralanmaların ani kanamaya yol açacağını ve kontrolünün güç olabileceğinden mutlaka bahsetmemiz gereklidir. Çevre dokuların osteotomi sırasında fibulanın iyi sıyrılması, ekartörler ile korunması bu sorunun oluşmasını önleyecektir. Ayrıca anterior kompartmandaki fasyanın sıkı kapatılmaması ve mutlaka içerideki hematomu boşaltıcı dren kullanılması önerilir.

\section{Damar Yaralanması}

Ostetomi sırasında düşük olsa da popliteal arter ve tibialis posterior sinirinin yaralanma şansı vardır. ${ }^{[28]}$ Bunu önlemek için tibianın arkasına Hohman ekartörlerin doğru yerleştirilmesi ve tibia posterior korteksinin hava kesici motor ile değil osteotom ile kesilmesi gereklidir. Ostetomi sırasında dizin $90^{\circ}$ fleksiyona getirilmesinin damar ve sinir yaralanmasını önleyeceğinden bahsedilse de, kadavra çalışmasında Georgoulis ve ark, fleksiyonun koruyucu etkisi olamadığını göstermiştir. Ayrıca tialis anterior kasının tibia yapışma yerinden iyi sıyrılması gereklidir. Çünkü tibialis anterior arterin rekurren dalı kolaylıkla kesilerek, kanamaya ve kompartman sendromuna yol açabilir. ${ }^{[28]}$

\section{HANGISI DAHA IYYi?}

\section{Proksimal Tibia Kapalı Kama Osteotomisi (PTKKO) ile Açık Kama Osteotomisinin (PTAKO) Karşılaştırılması}

PTKKO'li dizlerin 10 yıllık sağ kalımının \%74-97,6, 15 yılda \%56-93,2, 20 yılda \%66,9-85,1 arasında olduğu literatürde bildirilmiştir. Bu sağ kalım oranlarını açık kama osteotomilerle karşılaştırırsak; PTAKO'de beş yılda \%88,9-97, 10 yılda ise \%74-89 oranında olduğunu görürüz. ${ }^{[29]}$ PTAKO her ne kadar son yıllarda popülerlik kazansa da, PTKKO kadar uzun süreli izlemlere sahip değildir. Her iki osteotominin sonuçlarını karşılaştıran prospektif çalışma sayısı çok fazla değildir. ${ }^{[29-33]} \mathrm{Bu}$ çalışmalara göre iki osteotomi tipi arasında klinik olarak fark yoktur. Hatta van Egmond ve ark. ile Ishimatsu ve ark.'na göre PTKKO daha iyi sonuçlar verir. ${ }^{[29,31]}$ Meta-analizlere bakarsak; Sun ve ark. ile Smith ve ark., yaptıkları çalışmalarda, PTKKO ile PTAKO arasında bir fark bulmamışlardır ${ }^{[3,35]}$. Kim ve ark. ise 5. yılda aralarında fark bulamazlarken, 10 yılda PTAKO'nin PTKKO'ya göre daha iyi sonuçlar verdiğini göstermişlerdir. ${ }^{[33]}$ Tüm prospektif çalışmalar ve meta-analizlerin ışı̆̆ında, PTKKO ile PTAKO sonuçları arasında belirgin farkın bulunmadığını söyleyebiliriz. Aralarında en büyük fark; PTAKO ile amaçlanan düzeltme açılarına daha yüksek oranda ulaşıldığıdır. ${ }^{10]}$ Teorik olarak daha iyi bir mekanik aks daha iyi klinik sonucu beraberinde getirse de klinik sonuçlar üzerinde her zaman kesin katkısını göremiyoruz. ${ }^{[29]}$ Ayrıca iç yan bağ gevşekliğinde PTAKO'nin daha iyi sonuçlar verdiği Hoell ve ark. tarafından vurgulanmıştır. ${ }^{[30]}$ Bunun karşısında PTAKO patella yüksekliğini azaltarak, patellofemoral dinamiği bozabilir ve patellofemoral şikâyetleri arttırabilir. Patellofemoral eklem üzerine etkisini araştıran Ishimatsu ve ark. ise hibrit PTKKO'nin patellofemoral eklem uyumunu PTAKO'ye göre daha iyi düzelttiği ve patellofemoral artrozlu varus dizilimli hastalarda hibrit PTKKO'nin daha iyi sonuçlar verdiğini göstermiştir. ${ }^{[31]}$

İki osteotomi arasında total diz artroplastisine çevrilme oranlarının karşılaştırıldığı çalışmalardan Schallberger ve ark., iki osteotomi tipi arasında bir fark bulamamışlardır. Fakat bu çalışmada unutulmamalıdır ki PTKKO hasta sayısı, PTAKO oranla çok daha fazladır. ${ }^{[36]}$

Tibia üst ucunda sagittal planda gerçekleşen osteotomi sonrası değişikler gözetildiğinde, PTAKO'de tibial eğimin arttı̆̆ı, PTKKO'de ise azaldığı gösterilmiştir. ${ }^{[7,37]}$ Bu durumun sonuçları ne yönde etkileyeceği belirtilmese de, ÖÇB olmayan varus gonartrozlu dizlerde tibial eğimin azaltılması için PTKKO mekanik bir avantaj sağlayabilir. Tibial eğimi fazla olanlarda $\left(10^{\circ}\right.$ 'den fazla) tibial eğimin azaltılması tibianın öne kaymasını azaltacaktır. ${ }^{[38]}$

\section{PTKKO- Unikompartmantal Artroplasti (UKA) Karşılaştırılması}

Her ne kadar biyolojik bir yöntem olan osteotomi ile sentetik bir yöntem olan artroplastiyi karşılaştırmak doğru olmasa da, literatürde bu tür kıyasların çok olduğunu görüyoruz. Tackeuchi ve ark., 4-7 yıllık izlemde, PTKKO revizyon oranını (\%28), UKA revizyon oranına (\%20) göre daha yüksek bulmuştur. ${ }^{[39]}$ Fu ve ark., metaanalizde PTKKO'nin başarısızlık oranının \%11,6, UKA ise $\% 21$ olarak göstermiştir. ${ }^{[0]}$ Stokenborg-Colsman ve ark., osteotomi sağkalımının beş yıllık \%78, 10 yıllık, UKA'nin ise 5 yılda \%88, 10 yılda \%77 olarak 
bildirmiştir. ${ }^{[41]}$ Song ve ark., ilk 12 yılda PTKKO'nin UKA'den daha iyi sonuçlar verdiğini ama 12 yıl sonra bunun tersine döndüğünü göstermiştir. ${ }^{[42]}$ UKA'de en sık karşılaşılan femoral komponent gevşemesi sorununun genellikle ilk 10 yılda meydana geldiği, bunun olası nedeninin dizi ileri fleksiyonda zorlayan aktivitelerin femoral komponentte oluşturduğu aşırı stresler olduğu gösterilmiştir. ${ }^{[43]}$ Komponent dizilimi ve yaşam stili UKA'de başarıyı belirleyen faktörlerdir. Oysa PTKKO ile daha iyi eklem hareket açıklığı elde edilmiştir. ${ }^{[42]}$ Smith ve ark., PTKKO ile 60 yaşından ufak hastalar için daha maliyet etkili bir yöntem olduğunu, 60 yaşından sonra ise UKA'nin ön plana geçtiğini ortaya koymuştur. ${ }^{[44]}$ Sonuç olarak aynı demografik yapıya ve dize sahip hastalarda uzun dönemde PTKKO ile UKA arasında cerrahinin başarısı açısından büyük fark bulunamamıştır.

\section{SONUÇ: PTKKO BAŞARISI}

Hangi osteotomi şekliyle olursa olsun elde edilen başarı zamana yenik düşmektedir. Bu başarıya katkıda bulunan bir çok faktör sıralayabiliriz:

- Genç hasta

- Erken evredeki osteoartroz

- Osteotomi sonrası uygun mekanik aksın elde edilmesi ve bunun korunması

- Düşük kilo

- Epifizer varus deformitesinin varlı̆̆ı

- Cerrahi sırasında ve sonrasında komplikasyon oluşmaması

Belki de yöntemlerin birbirine olan üstünlüğünü tartışmayı bırakmalıyız. Bunun yerine hangi yöntemin hangi diz veya hasta için daha uygun olduğunu bulmak ve uygun implant seçimiyle birlikte hatasız cerrahi teknikler üzerine yoğunlaşmak bizi başarıya taşıyacaktır.

\section{KAYNAKLAR}

1. Coventry MB. Osteotomy of the upper portion of the tibia for degenerative arthritis of the knee: A preliminary report. J Bone Joint Surg Am 1965;47A(5):984-90. Crossref

2. Böhler M, Fuss FK, Schachinger W, Wölfl G, Knahr K. Loss of correction after lateral closing wedge high tibial osteotomy - a human cadaver study. Arch Orthop Trauma Surg 1999;119(3-4):232-5. Crossref

3. Müller W. High tibial osteotomy: Conditions, indications, techniques, problems, results. In: Thorngren KG, Soucacos PN, Horan F, Scott J, editors. European Instructional Course Lectures, Vol 5. London: The British Editorial Society of Bone and Joint Surgery, 2001; pp.194-206.

4. Paley D, Maar DC, Herzenberg JE. New concepts in high tibial osteotomy for medial compartment osteoarthritis. Orthop Clin North Am 1994;25(3):483-98.
5. Mont MA, Alexander N, Krackow KA, Hungerford DS. Total knee arthroplasty after failed high tibial osteotomy. Orthop Clin North Am 1994;25(3):515-25.

6. Insall J, Shoji H, Mayer V. High tibial ostetomy. A five year evalution. J Bone Joint Surg Am 1974;56A:1397-405. Crossref

7. El-Azab H, Glabgly P, Paul J, Imhoff AB, Hinterwimmer S. Patellar height and posterior tibial slope after open and closed wedge high tibial osteotomy: a radological study on 100 patients. Am J Sports Med 2010;38(2):323-39. Crossref

8. Yercan HS, Okcu G, Aydogdu S, Ozic U. Clinical results of lateral closing wedge high tibial osteotomy for osteoarthritis of the knee (Oblique osteotomy with tension band fixation). Acta Orthop Traumatol Turc 2004;38(2):89-95. http:// www.aott.org.tr/en/clinical-results-of-lateral-closing-wedgehigh-tibial-osteotomy-for-osteoarthritis-of-the-knee-obliqueosteotomy-with-tension-band-fixation-164847

9. Bauer GC, Insall J, Koshino T. Tibial osteotomy in gonarthrosis. J Bone Joint Surg Am 1969;51A(8):1545-63. Crossref

10. Duivenvoorden T, Brouwer RW, Baan A, Bos PK, Reijman M, Bierma-Zeinstra SA, Verhaar JAN. Comparison of closing wedge and openin wedge hihg tibial osteotomy for medial compartment osteoarthritis of the knee. A randomized controlled trial with a six year follow up. J Bone and Joint Surg Am 2014(17):96:1425-32. Crossref

11. Gaasbeek RDA, Nicolaas L, Rijnberg WJ, van Loon CJM, van Kampen A. Correction accuracy and collateral laxity in open versus closed wedge high tibial osteotomy. A one-year randomised controlled study. Int Orthop 2010;34(2):201-7. Crossref

12. Jackson JP, Waugh $\mathrm{W}$. The technique and complications of upper tibial osteotomy. J Bone Joint Surg Br 1974;56$\mathrm{B}(2): 236-45$. Crossref

13. Geiger F, Schneider U, Lukoschek M, Ewerbeck V. External fixation in proximal tibial osteotomy: a comparison of three methods. Int Orthop 1999;23(3):160-3. Crossref

14. Mynerts R. High tibial osteotomy with overcorrection of varus malalignment in medial gonarthrosis. Acta Orthop Scand 1980;51(1-6):557-60. Crossref

15. Holden D, James SL, Larson RL. Proximal tibial osteotomy in patients who are fifty years old or less. J Bone Joint Surg Am 1988;70A(7):977-82. Crossref

16. Aglietti P, Buzzi R, Vena LM, Baldini A, Mondaini A. High tibial valgus osteotomy for medial gonarthrosis: a 10-year study. J Knee Surg 2003:16(1):21-6.

17. Stuart MJ, Grace JN, Ilstrup DM, Kelly CM, Adams RA, Morrey BF. Late recurrence of varus deformity after proximal tibial osteotomy. Clin Orthop Relat Res 1990;260:61-5. Crossref

18. Rinonapoli E, Mancini GB, Corvaglia A, Musiello S. Tibial osteotomy for varus gonarthrosis. A 10-to 21-year follow-up study. Clin Orthop Relat Res 1998;353:185-93. Crossref

19. Bonnin $\mathrm{M}$, Levigne $\mathrm{CH}$. Osteotomie tibiale valgisation pour arthrose femoro-tibiale interne: resultats d'un échantillon de 217 ostéotomies revues avec un recul de 1 a 21 ans. Journées Lyonnaises de chirurgie du genou 1991;7:142-68.

20. Levigne $\mathrm{CH}$. Interet de l'axe épiphysaire dans l'arthrose. Journées Lyonnaises de chirurgie du genou 1991;7:127-41.

21. Hofmann AA, Wyatt RWB, Beck SW. High tibial osteotomy: Use of an osteotomy jig, rigid fixation, and early motion versus conventional surgical technique and cast immobilization. Clin Orthop Relat Res 1991;(271):212-7. Crossref 
22. Westrich GH, Peters LE, Haas SB, Buly RL, Windsor RE. Patella Height after high tibial osteotomy with internal fixation and early motion. Clin Orthop Relat Res 1998;354:169-74. Crossref

23. Insall JN, Joseph DM, Msika C. High tibial osteotomy for varus gonarthrosis. J Bone Joint Surg Am 1984;66(7):1040-8. Crossref

24. Tjornstrand BAE, Egund N, Hagstedt BV. High tibial osteotomy. A seven-year clinical and radiographic follow-up. Clin Orthop Relat Res 1981;(160):124-36. Crossref

25. Schatzker J, Burgess RC, Glynn MK. The management of nonunions following high tibial osteotomies. Clin Orthop Relat Res 1985;(193):230-3. Crossref

26. Aydoğdu S, Yercan H, Saylam C, Sur H. Peroneal nerve dysfunction after high tibial osteotomy. An anatomical cadaver study. Acta Orthop Belg 1996;62(3):156-60.

27. Kırgis A, Albrecht S. Palsy of the deep peroneal after proximal tibial osteotomy: An anatomical study. J Bone Joint Surg Am 1992;74A(8):1180-5. Crossref

28. Georgoulis AD, Makris CA, Papageorgiou CD, Moebius UG, Xenakis T, Soucacos PN. Nerve and vessel injuries during high tibial osteotomy combined with distal fibular osteotomy: a clinical relevant anatomic study. Knee Surg Sports Traumatol Arthrosc 1999;7(1):15-9. Crossref

29. van Egmond N, van Grinsven S, van Loon CJM, Gaasbeck RD, van Kampen A. Better clinical results after closed compared to open-wedge high tibial osteotomy in patients with medial knee osteoarthritis and varus alignment. Knee Surg Sports Traumatol Arthrosc 2016;24:34-41. Crossref

30. Hoell S, Suttmoeller J, Stoll V, Fuchs S, Gosheger G. The high tibial osteotomy, open versus closed wedge, a comparison of methods in 108 patients. Arch Orthop Trauma Surg 2005;125(9):638-43. Crossref

31. Ishimatsu $T$, Takeuchi R, Ishikawa $H$, Yamaguchi $Y$, Maeyama A, Osawa K, Jung WH. Hybrid closed wedge high tibial osteotomy improves patellofemoral joint congruity compared with open wedge high tibial osteotomy. Knee Surg Sports Traumatol Arthrosc 2019;27(4):1299-309. Crossref

32. Gaasbeek R, Welsing R, BarinkM, Verdonschot N, van Kampen A. The influence of open closed high tibial osteotomy on dynamic patellar tracking: a biomechanical study. Knee Surg Sports Traumatol Arthrosc 2007;15(8):978-84. Crossref

33. Kim JH, Kim HJ, Lee DH. Survival of opening versus closing wedge high tibial osteotomy: a meta-analysis. Sci Rep 2017;7(1):7296. Crossref
34. Sun H, Zhou L, Duan J, Li F. Comparison between closingwedge and opening-wedge high tibial osteotomy in patients with medial knee osteoarthritis: A systematic review and meta-analysis. J Knee Surg 2016;30(2):158-165. Crossref

35. Smith TO, Sexton D, Mitchell P, Hing CB. Opening or closing wedge high tibial osteotomy: a meta-analysis of clinical and radiological outcomes. Knee 2011;18(6):361-8. Crossref

36. Schallberger A, Jacobi M, Wahl P, Maestretti G, Jacob RP. High tibial valgus osteotomy in unicompartmental medial osteoarthritis of the knee: a retrospective follow-up study over 13-21 years. Knee Surg Sports Traumatol Arthrosc 2011;19(1):122-7. Crossref

37. Lustig S, Scholes CJ, Costa AJ, Coolican MJ, Parker DA. Different changes in slopes between the medial and lateral tibial plateau after open wedge high tibial osteotomy. Knee Surg Sports Traumatol Arthrosc 2013;21(1):32-8. Crossref

38. Neyret P, Zuppi G, Si Selmi TA. Tibial deflexion osteotomy. Oper Techn Sports Med 2000;8(1):61-6. Crossref

39. Tackeuchi $R$, Umemoto $Y$, Arateke M, Bito $H$, Saito I, Kumagai K, Sasaki Y, Akamatsu Y, Ishikawa H, Koshino T, Saito T. A midterm comparison of open wedge high tibial osteotomy vs. unicompartmental knee arthroplasty for medial compartment osteoarthritis of the knee. J Orthop Surg Res 2010;5(1):65. Crossref

40. Fu D, Li G, Chen K, Zhao Y, Hua Y, Cai Z. Comparison of high tibial osteotomy and unicompartmental knee arthroplasty in the treatment of unicompartmental osteoarthritis: a metaanalysis. J Arthroplasty 2013;28(5):759-65. Crossref

41. Stokenborg-Colsman C, Wirth CJ, Lazovic D, Wefer A. High tibial osteotomy versus unicompartmental joint replacement in unicompartmental knee joint osteoarthritis:7-10 year follow-up prospective randomised study. Knee 2001;8(3):187-94. Crossref

42. Song SJ, Bae DK, Kim KI, Park CH. Long term survival between closed wedge high tibial osteotomy and unicompartmental knee arthroplasty in patients with similar demographics. Knee Surg Sports Traumatol Arthrosc 2019;27(4):1310-9. Crossref

43. Zelle J, Janssen D, Van Eijden J, Malefijt MDW, Verdonschot $\mathrm{N}$. Doaes high flexion totalknee arthroplasty promote early loosening of the femoral component? J Orthop Res 2011;29(7):976-83. Crossref

44. Smith WB, Steinberg J, Scholtes S, McNamara IR. Medial compartment knee osteoarthritis: age-stratified costeffectiveness of the total knee arthroplasty, unicompartmental knee arthroplasty and high tibial osteotomy. Knee Surg Sports Traumatol Arthrosc 2017;25(3):924-33. Crossref 